\title{
Hacia un estudio de los antagonismos y las identidades políticas
}

\author{
Artículos originales: SOCIOLOGÍA \\ Recibido: 20/04/2021 \\ Aprobado: 12/06/2021 \\ Publicado: $14 / 10 / 2021$
}

\author{
Jorge Luis Duárez Mendoza \\ Universidad Nacional Mayor de San Marcos \\ jduarezm@unmsm.edu.pe
}

\begin{abstract}
RESUMEN
A partir de una crítica al denominado 'enfoque acotado de la política' que prioriza al régimen político como objeto de estudio y que ha sido preponderante en la ciencia política peruana durante los últimos ańos, el presente artículo propone una ruta alternativa en términos teórico-metodológicos para el estudio de los procesos políticos contemporáneos. Reconociendo la autonomía relativa de lo político, proponemos prestar atención al antagonismo y su operación en la constitución de las identidades políticas para el estudio de los procesos políticos. Sostenemos que para el estudio de los antagonismos el análisis de discurso nos brinda un instrumental sumamente útil. El artículo se encuentra organizado en tres apartados. En el primer apartado desarrollamos nuestra crítica al denominado enfoque de la política acotada, evidenciando sus límites heurísticos. En el segundo apartado presentamos los fundamentos conceptuales de nuestra propuesta, planteando una reflexión en torno al antagonismo y la distinción entre la política y lo político desde el enfoque posfundacional. En el tercer apartado profundizamos en los aspectos teórico-metodológicos de nuestra propuesta, basada en el análisis del discurso. Finalizamos nuestro artículo con algunas conclusiones en torno a la importancia del antagonismo para el análisis político, los alcances teórico-metodológicos de nuestra propuesta y los desafíos teóricos que identificamos para futuras investigaciones.
\end{abstract}

Palabras clave: antagonismo, identidades políticas, representación, discurso político.

\section{Towards a study of antagonisms and political identities}

\begin{abstract}
This paper proposes a theoretical and methodological alternative for the analyses of contemporary political processes. Also, it relies on criticism of the predominant analytical perspective in Peruvian political science during the last years, which prioritized the political regime as an object of study. By recognizing politics relative autonomy, we propose to pay attention to antagonism and its operative role in the composition of political identities to study political processes. We argue that discourse analysis is a useful analytical tool for studying political antagonisms. This article contains three sections. In the first section, we develop our critic to the predominant analytical perspective of political science in Peru, showing its heuristic limits. In the second section, we present our theoretical framework. Also, we reflect on antagonism and differences between polity and politics from a post-foundational approach. In the third section, we focus on the theoretical-methodological aspects of our proposal based on discourse analysis. Finally, we present some conclusions about the importance of antagonism for political analysis, a theoretical-methodological scope of our proposal, and identified theoretical challenges for future research.
\end{abstract}

KEYwORDs: antagonism, political identities, representation, discourse analysis. 


\section{Introducción $^{1}$}

Todos los ríos van al mar y el mar nunca se llena; al lugar donde los ríos van, allá vuelven a fluir.

Eclesiastés 1, 7.

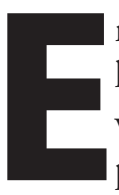

n el Perú desde los ańos 2000 la ciencia política ha ganado preponderancia en las universidades y en el debate público. Conceptos propios de esta disciplina, tales como régimen político, sistema de partidos, presidencialismo, sistema electoral, entre otros, han servido para interpretar la inestable política nacional (Tanaka, 2005; Dargent y Muñoz, 2012; Aragón e Incio, 2014). A diferencia de décadas anteriores en donde primaron miradas "estructuralistas" para analizar la política (las cuales consideraban factores económicos, ideológicos y geopolíticos para interpretar las relaciones de poder) la ciencia política contemporánea ha priorizado una mayor demarcación de su objeto de estudio enfocándose en la relación entre agentes e instituciones políticas. Y esto con la intención de preservar, conceptualmente, la autonomía de la política. Ahora bien, ¿será este el único camino para el análisis de los procesos políticos considerando la autonomía de la política? O acaso, ¿se podrán ensayar otras rutas de análisis sin desconocer la autonomía de la política?

El presente artículo propone una alternativa para el estudio de los procesos políticos, a partir de revisar el enfoque preponderante con el cual los politólogos y las politólogas peruanas han venido estudiando estos procesos durante los últimos años. Nos proponemos «abrir otro camino» para el análisis de lo político centrado en el antagonismo, aportando así a un pluralismo de enfoques teórico-metodológicos. Nuestro artículo está organizado en tres apartados. En el primero de ellos nos valemos de un importante trabajo de dos destacados politólogos peruanos, Alberto Vergara y Carlos Meléndez (2010), para presentar el enfoque preponderante de la ciencia política en el estudio de los procesos políticos. En el segundo apartado presentamos los fundamentos teóricos de nuestra propuesta de análisis, centrada en el antagonismo y las identificaciones políticas para el análisis de los procesos políticos. Nos valemos para ello de los apor-

1 Quiero agradecer los comentarios de Fernando Munguía, Cristian Acosta y Luis Purizaga a una versión anterior de este artículo. La responsabilidad de lo que aquí se expone es exclusivamente del autor tes de diferentes autores que identificamos, siguiendo a Marchart (2009), como representantes del enfoque posfundacional. En el tercer y último apartado nos avocamos a introducir algunos elementos teóricometodológicos para el estudio de los procesos políticos desde el enfoque que proponemos. Estos elementos se basan en el análisis de discurso. Finalizamos el presente artículo con algunas conclusiones en torno a la importancia del antagonismo para el análisis político, los alcances teórico-metodológicos de nuestra propuesta y los desafíos teóricos que identificamos para futuras investigaciones. ${ }^{2}$

\section{La ciencia política en el Perú y la especificidad de la política}

En un libro publicado en 2010 titulado La iniciación de la política. El Perú político en perspectiva comparada, los destacados politólogos peruanos Alberto Vergara y Carlos Meléndez elaboraron una suerte de «estado de la cuestión» en torno al estudio de los procesos políticos en el Perú, proponiendo una clave de lectura basada en la distinción entre ciertos autores que asumirían una concepción «vasta» de la política y otros que tendrían más bien una concepción "acotada» de la misma. En el primer grupo Vergara y Meléndez ubican a autores tales como Julio Cotler (1978), Sinesio López (1997) y Carlos Franco (1998); y en el segundo grupo posicionan a Cynthia Sanborn (1991), Fernando Tuesta (1996), Martín Tanaka (1998) y Henry Pease (1999). La concepción vasta de la política se caracterizaría, según Vergara y Meléndez, por la exigencia de analizar la política considerando experiencias históricas de largo alcance, vinculándola con los distintos subsistemas que configuran el sistema social. La concepción acotada, por el contrario, se identificaría por un tipo de estudio que privilegia el análisis de la política desde un marco temporal más restringido, prestando atención a la interacción entre los agentes y las instituciones políticas.

Para profundizar en la concepción vasta de la política, Vergara y Meléndez se detienen en el trabajo de Carlos Franco titulado Acerca de los modos de pensar la

2 Vale la pena señalar que, si bien nuestro artículo entabla un diálogo particular con la ciencia política peruana, los fundamentos teóricometodológicos de nuestra propuesta trascienden el «caso peruano». 
democracia en América Latina (1998). ${ }^{3}$ En esta obra, Franco nos propone una crítica a la reflexión de la democracia y su modo preponderante de pensarla desde finales de los años setenta en nuestra región, producto de un particular clima político-intelectual, de la crisis de la teoría de la dependencia y del abandono de fundamentos histórico-comparados en el análisis social (2013:23). Según Vergara y Meléndez, el trabajo de Franco nos plantea la exigencia de analizar la política vinculándola a las experiencias históricas de cada sociedad, identificando sus relaciones con la economía, la cultura y los procesos geopolíticos. Es decir, para Franco «la dinámica política depende en gran medida de lo que ocurre en la base social del país, por lo cual las instituciones formales reciben menor importancia» (Vergara y Meléndez, 2010:17). En términos metodológicos podríamos decir que la política desde esta concepción es asumida como una variable dependiente de múltiples variables independientes: «...en esta vertiente de investigación $<<$ lo político >> está enraizado en múltiples esferas (sociales, internacionales, económicas, culturales, etcétera) lo que implica conocer muchas de esas raíces para poder responder a la pregunta de investigación. De ahí que sea una apuesta por una política vasta» (Vergara y Meléndez 2010:17).

De lo anterior se infiere que el costo de apostar por una concepción vasta de la política sería la renuncia teórica y metodológica de la «autonomía de la política». Es decir, si la política es pensada desde sus condicionantes, entonces el margen de maniobra de los actores políticos y de las instituciones del régimen político quedaría limitado a la función que cumple una suerte de "super estructura» (recordando aquella vieja metáfora marxista).

Dicho lo anterior, vale la pena hacer acá una breve disquisición en torno a la propuesta de Franco que no es destacada por Meléndez y Vergara (probablemente porque no era útil para los fines de su argumentación). Luego de su crítica a los estudios de la transición democrática (que progresivamente tomaron fuerza en América Latina a partir de los ańos ochenta), Franco planteó para el estudio de los procesos políticos un enfoque teórico probabilístico, el cual suponía la complementariedad entre la necesi-

3 Existe una reedición de este título publicada en el 2013 por la editorial de la Universidad Nacional de Lanús, Argentina. dad (producto de las condiciones histórico-estructurales de las sociedades) y la contingencia (relacionada con la acción de los agentes). Franco buscó debilitar el férreo estructuralismo que habría estado presente en las formas de pensar la política durante buena parte del siglo XX (en la Teoría de la Dependencia, por ejemplo), para con ello enriquecer nuestra capacidad heurística de los procesos políticos contemporáneos. Ahora bien, a nuestro juicio la crítica de Franco al modo de pensar la democracia por parte de los teóricos de las transiciones a la democracia lo llevó a enfatizar en los condicionamientos y no a profundizar en la dimensión contingente que opera en los procesos políticos, ni ir más allá de su mera enunciación. Dar prioridad a la contingencia, es lo que habilita pensar en el carácter propio de lo político trascendiendo una mirada institucionalista. ${ }^{4} \mathrm{Y}$ en esto Franco no profundizó en términos conceptuales. ${ }^{5}$

Pero volvamos a la distinción que nos proponen Meléndez y Vergara. Como ya hemos señalado, en la otra orilla de la política vasta se encuentra la política asumida de forma acotada. Los autores toman como ejemplo de esta segunda concepción el trabajo titulado Los espejismos de la democracia. El colapso del sistema de partido en el Perú, 1980-1995, en perspectiva comparada, escrito por Martín Tanaka (1998), pues allí identifican que son los agentes y las instituciones los que son conceptualizados como variables explicativas de los procesos políticos. En este trabajo, Tanaka nos brinda una explicación sobre el derrumbe del sistema de partidos en el Perú producto de una crisis de representatividad. Desde esta concepción de la política acotada se plantearía «una investigación politológica separada del resto de disciplinas de las humanidades y las ciencias sociales» (Vergara y Meléndez, 2010:20). La principal virtud de esta perspectiva sería el reconocimiento de la autonomía de la política. Si bien

4 Nótese que apelamos al concepto de lo político y no al de la política. Mientras lo político nos remite al momento disociativo que interrumpe el orden social, la política refiere a las reglas, procedimientos e instituciones que definen al régimen político. En el siguiente apartado profundizaremos en esta distinción conceptual.

5 Cabe agregar que coincidimos con la crítica que hace Franco a lo que denominó la "nueva forma de pensar la democracia» en tanto esta ha sustentado teóricamente el estudio de los regímenes políticos en América Latina desde las experiencias del occidente europeo, lo cual ha generado que los politólogos terminen estudiando aquello que a las democracias en esta parte del hemisferio le haría falta y no aquello que las definen. Es decir, paradójicamente se intenta explicar la presencia a través de las ausencias. 
se reconocería la importancia de factores, tales como el desarrollo social para entender la fortaleza de una democracia, estos factores «externos» no cumplirían una función sustantiva en el análisis. Nos encontraríamos ante un enfoque que:

... privilegia el análisis de la política desde un marco temporal acotado, donde las preguntas de investigación se responden desde la forma en que interactúan los actores políticos con las instituciones políticas, que se enmarca en las discusiones vinculadas a la $<<$ consolidación $>>$ de la democracia y que está guiada por un tipo determinado de teoría (Vergara y Meléndez 2010:22).

Una vez presentadas ambas concepciones de la política, Meléndez y Vergara sostienen que son conscientes que sea cual sea el camino que optemos para el análisis de los procesos políticos, este tendrá ventajas y desventajas. Si asumimos el camino de la política vasta nos adentraríamos a una mirada compleja de la política pero que costaría mucho "aterrizarla» al análisis empírico. Si elegimos el camino de la política acotada podríamos realizar análisis basados en evidencia y en comparaciones, pero corriendo el riesgo de posibles reduccionismos. Ahora bien, los autores remarcarán que no se tiene por qué asumir que ambos caminos son irreconciliables, sino más bien lo que se debería buscar es «tender un puente» entre ambas concepciones. ${ }^{6}$

Si bien los autores expresan una actitud conciliadora entre lo que denominan la política vasta y la política acotada, también hacen evidente una toma de posición. Es claro el camino que Meléndez y Vergara eligen. El pie de página número cuatro de la introducción de La iniciación de la política... es bastante elocuente en torno al interés teórico y metodológico de los autores: el análisis del régimen político democrático. Con la intención de salvaguardar en el análisis la autonomía de la política, los autores apuestan por una aproximación que privilegie al régimen político, es decir al conjunto de instituciones, procedimientos y reglas en torno al Estado y las políticas públicas, como «esfera primordial para la ciencia

6 «Vale decir, lo repetimos, en la mayoría de casos las diferencias no son irreconciliables, sino más bien, están atravesadas por una cuestión de énfasis en algunas dimensiones en lugar de otras" (2010:23). política» (2010:25). ${ }^{7}$ Desde esta apuesta plantean su interés por construir una ciencia política pluralista en la que convivan diferentes perspectivas teóricas.

A nuestro juicio el informe titulado Hacia la Democracia del Bicentenario (2019) elaborado por la Comisión de Alto Nivel para la Reforma Política en el Perú puede ser identificado como un ejemplo (quizás el mejor logrado) de la apuesta realizada por Meléndez y Vergara. ${ }^{8}$ Este informe presenta una propuesta para avanzar en una reforma institucional de la política en el Perú, considerando tres sistemas interrelacionados entre sí: el sistema de gobierno, el sistema electoral y el sistema de partidos. La propuesta de la comisión parte de un diagnóstico que tiene como eje central la crisis de la representación política en el Perú, identificando su génesis a inicio de los ańos noventa con el «colapso» del sistema de partidos. Lo que habría primado desde entonces en la política peruana sería el fraccionamiento y el bajo nivel organizativo de los partidos políticos, la desinstitucionalización de la política y la desafección ciudadana. Frente a esta situación (y considerando los tres sistemas antes mencionados) la comisión planteó su propuesta sobre la base de cuatro ejes: anticorrupción y rendición de cuentas, gobernabilidad, organizaciones políticas y representación; y participación electoral y política (2019:21-62). Por lo hasta aquí referido queda clara la sintonía entre la propuesta de la comisión y el enfoque de la política acotada planteada por Meléndez y Vergara. Y queda evidenciada también su límite: el pensar la representación política exclusivamente dentro de los linderos del régimen político.

Consideramos que el principal límite o desventaja del enfoque de la política acotada reivindicado por Meléndez y Vergara consiste en que el carácter objetivo y positivo del régimen político no es problematizado. Determinados conflictos sociales evidencian que las tensiones que surgen en el régimen político no se reducen a las fricciones que se suceden al interior de este, sino en la relación entre institucio-

7 Apelamos aquí a la definición que O’Donnell (2002:55) da al concepto de régimen político.

8 La Comisión de Alto Nivel para la Reforma Política fue constituida por el gobierno de Martín Vizcarra el 21 de diciembre del 2018, con el objetivo de proponer las normas que sean necesarias para avanzar en una reforma política en el Perú. La comisión estuvo conformada por Fernando Tuesta, Paula Muńoz, Milagros Campos, Jessica Bensa y Martín Tanaka. Nótese que dos de los comisionados (Tuesta y Tanaka) son representantes de lo que Meléndez y Vergara identifican como la concepción acotada de la política. 
nes que lo conforman y lo que los agentes son fuera de este. Por ejemplo, durante el segundo gobierno aprista se aprobaron un conjunto de incentivos para promover actividades extractivas en la Amazonía sin considerar los estilos de vida de las comunidades indígenas que habitaban dicho territorio, negando así su estatus ciudadano. Nos encontramos frente a subsistemas que se relacionan desde sus precariedades, desde el no encontrarse plenamente constituidos, en donde elementos «políticos», «económicos» y «culturales» entran en relaciones inestables de imbricación (Laclau, 1993).

Dicho todo lo anterior, debemos señalar que coincidimos en parte con Meléndez y Vergara en el presupuesto de que un fructífero estudio de los procesos políticos demanda no asumir a estos como efectos necesarios de causas estructurales que las exceden, pero, sostenemos que un adecuado enraizamiento de esta autonomía no se logra apelando al régimen político, sino a una dimensión más fundante, de carácter ontológica que nos brinda el concepto de antagonismo. ${ }^{9}$ Dicho lo anterior podemos afirmar que para comprender los procesos políticos en su carácter propio no tenemos como única opción el elegir al régimen político como objeto de estudio, sino que podemos optar por otros caminos. En el siguiente apartado introduciremos algunas cuestiones teóricas que nos permitirán fundamentar esta propuesta, destacando principalmente la relación entre lo político y el antagonismo.

\section{El antagonismo como locus de atención}

Para iniciar este apartado daremos una definición preliminar del antagonismo entendida como el límite de toda objetividad social (Laclau, 1993). Y decimos «límite» porque el antagonismo nos enfrenta con lógicas que resultan inconmensurables entre ellas, es decir, no reconciliables, haciéndose inevitable el momento del poder. En las siguientes líneas nos adentramos a un nivel de análisis diferente del tratado en el

9 Establecer la autonomía de la política ha sido un tópico recurrente en la ciencia y la teoría política. Trabajos como los de Schmitt (1932), Dahl (1961), Skocpol (1985) y Arendt (1997) son solo algunos ejemplos que han trabajado este tópico desde diferentes enfoques. En el caso particular del marxismo, una aproximación a los vaivenes en torno a este tema lo encontramos, por ejemplo, en Althusser (2003) y Aricó (2011). primer apartado. Nos trasladaremos de la dimensión de la política (el régimen político) a la dimensión del antagonismo. Para ello necesitaremos enriquecer nuestro instrumental conceptual, apelando para ello a lo que Marchart (2009) ha denominado una perspectiva posfundacional para pensar el orden social.

El pensamiento político posfundacional postula el carácter fundante de las relaciones de poder en el orden social. Esta perspectiva no apela a ningún tipo de determinación en última instancia que definiría el orden social. Eso sí, a diferencia del antifundacionalismo, "no intenta borrar por completo esas figuras del fundamento, sino debilita su estatus ontológico» (Marchart, 2009:14-15). Este debilitamiento ontológico no nos conduce al supuesto de la ausencia total de fundamento alguno (lo cual nos dejaría en el terreno de la pura dispersión de la heterogeneidad social), sino más bien supone la imposibilidad de un fundamento último que determine el orden social, lo cual es algo enteramente distinto, pues implica la creciente conciencia, por un lado, de la contingencia $y$, por el otro, de lo político como el momento de un fundar parcial y, en definitiva, siempre precario de un orden social, capaz de ser subvertido (Marchart, 2009). La modernidad europea, por ejemplo, fundó la democracia liberal sobre los principios de la libertad individual y la igualdad ante la ley (Bobbio, 2010), principios que fueron posteriormente cuestionados (y hasta cierto punto resignificados) por el emergente movimiento obrero desde mediados del siglo XIX. En el Perú de la denominada «República Aristocrática» (1895-1919) las élites gobernantes fundaron su dominio sobre las bases del liberalismo y de la regeneración social (Garavito, 1989; Ccahuana, 2020), bases que fueron cuestionadas por el aprismo y el socialismo emergentes hacia finales de los años veinte. Lo político, desde la perspectiva posfundacional es, en definitiva, esta disputa por la constitución de un orden social, por la definición (parcial) de sus fundamentos.

Dicho lo anterior, debemos ahora incluir una distinción conceptual que resulta fundamental: la distinción entre la política y lo político. Siguiendo a Mouffe (2009:15-40), consideramos que, mientras la política nos remite al régimen político definido por reglas, procedimientos e instituciones (el objeto de estudio que interesa a Vergara y Meléndez), lo político nos remite a la constitución de las identidades 
políticas y a las disputas entre estas por la institución de un orden social. Tal como lo mencionamos en el párrafo anterior, en lo político está en juego la búsqueda de fundamentos para organizar la vida social, una empresa que siempre resulta inacabada, precaria, abierta, pero a la vez indispensable. ${ }^{10}$ La distinción entre la política y lo político nos habilita una dimensión analítica de los procesos políticos que no es suficientemente atendida por el enfoque de la política acotada asumida por Meléndez y Vergara, sin renunciar al presupuesto de la autonomía de la política pero enraizándola en su dimensión ontológica.

Nos aproximamos a lo político desde lo que Marchart (2009:63-67) ha denominado el «rasgo schmittiano", es decir, al momento disociativo del mismo. Asumiendo esta perspectiva entendemos lo político como antagonismo, es decir, prestamos atención a las formas colectivas de identificación basadas en lógicas de oposición. ${ }^{11}$ El tipo de relación nosotros/ellos que el antagonismo establece supone el reconocimiento de una alteridad que amenaza la identidad del «nosotros». Por ejemplo, redefiniendo el imaginario político aprista Alan García planteó durante su segundo gobierno (2006-2011), la distinción entre "pueblo / minorías anticapitalistas y estatistas", identificando en el primero a una mayoría popular que se beneficiaba de la inversión y el crecimiento económico generado por el empresariado y que era representado por el "Partido del Pueblo»; y en el segundo a grupos "anti-sistema", a "perros del hortelano" financiados por intereses extranjeros que impedían el desarrollo nacional y que, por tanto, debían ser reprimidos (Duárez, 2018). Lo que está aquí en juego es una concepción relacional de las identidades políticas, es decir, no postulamos que estas se encuentren plenamente constituidas, sino más bien que son constituidas en función de las diferencias que entablan frente a "otros» que son identificados como amenazas para su realización. En tal sentido, podemos afirmar que toda identidad política está habitada

10 Sobre la distinción conceptual entre la política y lo político ver Marchart (2009: 55-86).

11 A diferencia del rasgo schmittiano, Marchart (2009:59-63) sostiene que el "rasgo arendtiano» de lo político tiene como punto de partida el momento asociativo, es decir, concibe lo político como expresión de la comunalidad que se interesa por los asuntos públicos. Cabe señalar que el rasgo schmittiano de lo político no supone la imposibilidad de lograr consensos, más bien busca comprender la constitución de estos a partir de los antagonismos que les dan forma. por el espectro de su contrario. ${ }^{12}$ Prestar atención a los antagonismos trae como consecuencia reconocer que «Las cuestiones propiamente políticas siempre implican decisiones que requieren que optemos entre alternativas en conflicto» (Mouffe, 2009:17) e irreductibles en términos racionales. ${ }^{13}$

Si la institución de un orden social es siempre precaria, siempre podrán manifestarse antagonismos que disloquen la estructura de dicho orden. En consecuencia, siempre será posible el momento de lo político evidenciando así los límites de la topografía social (incluido el régimen político). ${ }^{14} \mathrm{El}$ momento de lo político, como momento disociativo, podrá entonces emerger desde distintos tipos de relaciones sociales: en las relaciones laborales, en las relaciones religiosas, en las relaciones de género, entre otras, y no exclusivamente al interior del subsistema político. Esta emergencia, incluso, se haría más recurrente en sociedades donde prima una precaria institucionalidad política, como es el caso peruano. En torno a esta posibilidad de emergencia del antagonismo Mouffe sostiene lo siguiente:

...La distinción nosotros/ellos, que es condición de la posibilidad de formación de identidades políticas, puede convertirse siempre en locus de un antagonismo. Puesto que todas las formas de la identidad política implican una distinción nosotros/ellos, la posibilidad de emergencia de un antagonismo nunca puede ser eliminada. Por tanto, sería una ilusión creer en el advenimiento de una sociedad en la cual pudiera haberse erradicado el antagonismo (Mouffe 2009:23).

Como se deduce de lo hasta aquí planteado, no proponemos una disquisición conceptual en torno a la autonomía relativa de lo político apelando a una

12 Acá nos basamos en el concepto de "exterior constitutivo" trabajado por Staten (1984) y que ha sido utilizado por Laclau (2006) y Mouffe (2009) para dar cuenta de la función del establecimiento de una diferencia para la constitución de una identidad.

13 Para profundizar en la relación entre antagonismo e identificaciones políticas sugerimos revisar los trabajos de: Laclau y Mouffe (2004); Zizek (1989:23-31); y Mouffe (2000; 2009; 2014).

14 Ranciere (1996) ha destacado el valor del acontecimiento para pensar la dimensión disruptiva de lo político. Sin embargo, desde nuestro punto de vista al filósofo francés le interesa destacar el acontecimiento político como una excepción frente a la rutina de la política institucionalizada. A nosotros nos interesa más bien no pensar lo político como un acontecimiento excepcional, sino como aquella dimensión antagónica que está siempre latente en todo orden social. 
topografía de lo social, sino a una autonomía de lo político como momento disociativo que pone en entredicho al propio orden social. Nuestra afirmación de la autonomía relativa de lo político se basa en la crítica a todo intento por fundar esta práctica en alguna otra lógica, ya sea la económica o la cultural; o «encorsetarla» exclusivamente al régimen político. Ahora bien, el antagonismo acontece en un contexto histórico determinado y, por tanto, adquirirá características en función de las posibilidades que se disponen dentro de un orden social particular. ${ }^{15}$

Pensar lo político nos lleva a considerar esa compleja relación entre un orden social que siempre permanece infundable (en el nivel ontológico), pero que también está parcialmente fundado por prácticas sedimentadas (el nivel óntico). Por ejemplo, en las democracias liberales contemporáneas la emergencia de antagonismos y su presentación ante la opinión pública estará condicionada por las reglas, procedimientos y las instituciones del régimen político. En tal sentido, si bien priorizamos en nuestra aproximación analítica el momento del antagonismo, debemos dar «espacio al juego entre la política y lo político sin subsumir a ninguno de ellos bajo el otro" (Marchart, 2009:214). Esto en términos teórico-metodológicos implica prestar atención a las condiciones institucionales del régimen político en las cuales emerge el antagonismo.

\subsection{En torno a la representación política}

Habiendo presentado el campo de estudio que se nos apertura al incluir al antagonismo en nuestro análisis, podemos pasar ahora a destacar como este enfoque nos ayuda a pensar un problema de la política contemporánea como lo es la crisis de la representación. Considerar al antagonismo nos permite transcender una mirada procedimental de la representación, indagar sobre sus mecanismos más allá del sistema de partidos o del sistema electoral. Y es que si bien esta-

15 Quizás ayuda a esclarecer este argumento las siguientes líneas que tomamos de De Ípola (2007:198) quien citando las conocidas líneas del 18 Brumario de Marx <<Los hombres hacen su propia historia [...] no la hacen a su libre arbitrio, bajo circunstancias elegidas por ellos mismos, sino bajo aquellas circunstancias con que se encuentran directamente, que existen y que han sido legadas del pasado >> agrega lo siguiente: «queda en pie que, como lo hizo notar Sartre hace casi cincuenta ańos, son los hombres y no las circunstancias -que pueden ser escollos, pero también medios- quienes hacen la historia». mos de acuerdo con la Comisión de Alto Nivel para la Reforma Política en que nos encontramos frente a una "crisis de representación» que corroe la legitimidad de instituciones claves del régimen político como es el caso del Parlamento, reconocemos también que la representación opera más allá de los linderos institucionales. Resultará entonces valioso identificar también qué características adquiere la representación en estos ámbitos «extrainstitucionales».

Analizar lo político desde su carácter antagónico nos ayuda a profundizar en el problema de la representación, el problema que consideramos principal en la política peruana. Por ejemplo, si prestamos atención a los conflictos socioambientales podremos identificar cómo viene operando la representación a través de la acción de diferentes agentes, con sus logros, limitaciones y desafíos (Duárez, 2020). ${ }^{16}$ Para ello debemos evitar caer en el reduccionismo de que solo existe representación política a través del sistema de partidos. Este, en su intención de institucionalizar aquel, puede fracasar lo cual no implica que la representación política deje de operar.

Pero vayamos por partes. Para llevar a cabo una empresa como la sugerida en el párrafo anterior debemos ampliar las formas en que usualmente pensamos a la representación, entre ellas aquella que la asume como una lógica agregativa de intereses en la relación entre representante y representados. Consideramos que Ernesto Laclau en La razón populista (2006) nos brinda algunas herramientas conceptuales para ello. En dicho trabajo el teórico argentino subraya la relevancia de la dimensión simbólica de la representación dando cuenta de cómo a través de ella se generan formas colectivas de identificación. Para ello, Laclau nos propone pensar la representación desde una lógica bidireccional, es decir, no solo prestando atención a cómo los representantes deben considerar las demandas o aspiraciones de los representados, sino también la intervención de los representantes, en tanto éstos deben hacer creíble que las demandas particulares de los representados (por ejemplo, los trabajadores de la agro-exportación de la costa peruana o las trabajadoras del hogar) forman parte del interés general (pp. 199-201). En otras palabras, los representantes para tener éxito en su función deben imprimir un sentido que no estaba presente previamente en las demandas

16 Profundizaremos sobre este punto en el siguiente apartado. 
y aspiraciones de los representados. La operación de estos sentidos tiene consecuencias a nivel identitario. Por ello Laclau nos propone comprender la representación como proceso de construcción de identificaciones políticas.

El caso del peronismo durante las décadas de 1960 y 1970 analizado por Laclau (2006:266-274) nos puede ayudar a ilustrar lo arriba planteado en torno a la representación. Derrocado en 1955, Perón desde el exilio fue un férreo opositor a los gobiernos antiperonistas que gobernaron la Argentina durante 18 años. Por aquellos años Perón se vio limitado a enviar correspondencia privada, casetes e indicaciones verbales a una heterogénea resistencia peronista que se venía organizando en las fábricas, en barrios obreros y entre estudiantes, quienes imprimían a los mensajes de su líder una multiplicad de sentidos. La palabra de Perón operaba imprimiendo una unidad simbólica en todas las luchas dispersas de la resistencia peronista, cada una de las cuales, a su vez, le brindaba un significado particular. La demanda del regreso de Perón a la Argentina operaba como un significante unificador de esta heterogénea resistencia. En otros términos, la representación política en este caso operaba a través de asociaciones equivalenciales que posibilitaron la articulación de diferentes agentes, sin que se eliminen sus diferencias, que en el caso del peronismo de aquellas décadas era evidente entre los sindicatos peronistas, las organizaciones de jóvenes de izquierda y los grupos guerrilleros peronistas. ${ }^{17}$ Con el retorno de Perón a la Argentina y su ascenso al poder en 1973, el flamante presidente debía dotar de una regularidad institucional a las asociaciones equivalenciales que habían permitido mantener unificado al movimiento peronista. Sin embargo, el presidente Perón no pudo lograr este desafío y las asociaciones equivalenciales implosionaron al primar las diferencias antagónicas entre la burocracia sindical por un lado y las organizaciones de jóvenes de izquierda y los grupos guerrilleros por el otro. ${ }^{18}$ De esta manera se cerró un dramático ciclo de la representación peronista.

17 Sobre las lógicas equivalenciales en los discursos políticos ver: Laclau, 2006:103-110.

18 Vale la pena seńalar que nuestra coincidencia con la forma en que Laclau entiende la representación política no implica que compartamos su forma de entender el populismo. Para una aproximación a las críticas realizadas a la "La razón populista» de Laclau sugerimos revisar el trabajo de Suárez (2015).
Como podemos apreciar del ejemplo anterior, los procesos de significación implicados en la representación política operan a través de significantes con la capacidad de estructurar discursos que orientan la acción colectiva. El carácter de estos significantes puede ser de diversa índole, por ejemplo, pueden ser conceptos de la política moderna tales como «libertad» o «soberanía»; o referir a líderes políticos, tales como «Perón» o «Fujimori». Lo que está aquí en juego es pensar la representación política no solo como la relación que permite enunciar y canalizar demandas, sino también como un proceso de articulación de diferentes agentes en torno a un horizonte de sentido compartido que posibilita la emergencia de identificaciones políticas.

\section{El análisis del discurso como orientación teórica-metodológica}

En la primera sección de este artículo nos referimos a la forma en que en los últimos ańos la ciencia política en el Perú ha planteado el estudio de los procesos políticos desde una concepción acotada de la política. Con el fin de velar por la autonomía de la política, vimos como Vergara y Meléndez proponen al régimen político como objeto de estudio. Sin desconocer la validez de esta perspectiva, en la segunda sección hemos propuesto un camino alternativo para el estudio de los procesos políticos prestando atención al antagonismo. En este tercer y último apartado profundizaremos en cuestiones teórico-metodológicas. Nos interesa plantear algunas pautas para el análisis de los procesos políticos basados en el análisis del discurso.

La premisa fundamental del enfoque teóricometodológico que proponemos para el análisis de los procesos políticos es el carácter ontológicamente constitutivo de la discursividad con respecto a la realidad social. Nuestro enfoque se basa principalmente en los aportes de dos destacados teóricos, el ya citado Ernesto Laclau y Eliseo Verón. Si bien ambos autores desarrollaron sus proyectos intelectuales en paralelo, es decir, no entablaron un intercambio académico, consideramos que ciertos aportes que realizaron al análisis del discurso pueden integrarse, debido a que ambos comparten la premisa fundamental presentada al inicio de este párrafo (Retamozo y Fernández, 
2010:240). ${ }^{19}$ A su vez, los aportes de Laclau y Verón nos permiten, como veremos, aproximarnos a las lógicas disociativas del antagonismo.

Desde nuestro enfoque, el análisis de discurso contribuye a la comprensión de los procesos políticos indagando en la conformación de las identificaciones políticas y la emergencia de los antagonismos. Para esta indagación tendremos que prestar atención a la producción y los desplazamientos que experimentan los sentidos que orientan la acción colectiva. Antes de continuar, evitemos malentendidos. Cuando hablamos de análisis del discurso no nos estamos refiriendo a un análisis restringido a lo lingüístico o a la semiótica (como un lector apresurado podría creer). Cuando hablamos de «discurso» nos estamos refiriendo más bien a la producción social de sentidos que constituye a una sociedad como tal (Laclau, 1985). $\mathrm{O}$, en otras palabras, concebir los procesos sociales (incluidos los políticos) como procesos de producción de sentidos (Verón, 2004). El discurso adquiere centralidad en nuestro análisis en tanto nos permite aproximarnos a la lógica de la disputa política: «En efecto, el análisis del discurso no será el mero estudio de aspectos y controversias lingüísticas, sino que se convertirá en un instrumental teórico para abordar los espacios de constitución de la sociedad y las identidades políticas» (Retamozo y Fernandez 2010:17).

De hecho, podemos afirmar que el análisis del discurso es más que un método, es una ontología de lo social en la medida que parte de la premisa que todo proceso social supone procesos de significación. Desde el análisis del discurso que aquí proponemos el sentido no es un "reflejo" de una realidad exterior, sino que es constitutiva a esta (Sigal y Verón, 2010). Para una mejor comprensión de lo hasta aquí planteado pasaremos a presentar un estudio de caso en donde podremos identificar como opera nuestro enfoque teórico-metodológico.

19 Aunque esta consideración va en contra de la opinión del propio Laclau. En una conferencia dictada a la Federación de Docentes de la Universidad de Buenos Aires en septiembre del 2013, Laclau señaló que su propuesta teórica y la propuesta de Verón eran inconmensurables. Lamentablemente nuestro autor no dio mayor argumentación a su opinión. Una propuesta integradora de los aportes de Verón y Laclau sobre el análisis del discurso la encontramos en Aibar (2003). Para una aproximación a las coincidencias entre las propuestas de Laclau y Verón ver el citado trabajo de Retamozo y Fernández (2010).

\subsection{Espinar: la emergencia del antagonismo ${ }^{20}$}

En una investigación que realizamos sobre el conflicto socioambiental acaecido en la localidad cusqueña de Espinar en el año 2012, prestamos atención a cómo se constituyeron las identificaciones políticas de los agentes locales (organizaciones urbanas, campesinas y autoridades municipales) que lideraron las protestas frente al accionar de la empresa minera. A través de nuestro análisis buscamos desentrañar una complejidad sociopolítica que la prensa limeña solía presentar con bastante simplicidad. Para ello nos planteamos la siguiente pregunta: ¿cómo se constituyeron las identificaciones políticas de los agentes locales involucrados en el conflicto socioambiental ocurrido en Espinar durante los años del último boom minero? Para responder cabalmente esta pregunta reconocimos que era importante dar cuenta de ciertas decisiones gubernamentales y dinámicas de la industria minera que venían sucediendo en las últimas décadas. Por una parte, identificamos que la expansión de la minería a gran escala en el Perú estaba relacionada a: reformas de los marcos regulatorios realizadas en los años noventa que alentaban las inversiones; la decisión de los sucesivos gobiernos por legitimar esta actividad extractiva a través de medidas redistributivas de la renta (a través de canon); y mensajes que destacaban el impacto modernizador de la minería en las zonas del país más golpeadas por la pobreza. A su vez, las transformaciones de la industria minera a nivel global, relacionadas a: los avances tecnológicos para la explotación a tajo abierto; la alta demanda de minerales por parte de países emergentes tales como la China; y el incremento del precio de los minerales, permitieron un nuevo flujo de capitales que generaron un boom minero desde mediados de los noventa hasta los primeros años de la pasada década. En síntesis, reconocimos que considerar factores vinculados al régimen político y a la actividad económica —en este caso de la industria minerapermitían una mejor comprensión de lo sucedido en Espinar.

En nuestros diálogos con los agentes locales involucrados en las protestas del 2012, encontramos que las descripciones que hacían de los cambios que había experimentado Espinar producto de la activi-

20 Este apartado se basa en Duárez (2017). 
dad minera coincidían en referir a la disolución de las lógicas comunales, la contaminación de ríos y afluentes y el enfrentamiento entre organizaciones y comunidades por estar a favor o en contra de la actividad extractiva. La consigna que articuló a las organizaciones urbanas, campesinas y a las autoridades locales en las protestas fue lograr lo que podíamos denominar una "Convivencia en Armonía» con la empresa minera. Para ello plantearon la necesidad de que la empresa minera destine una mayor cantidad de recursos para el desarrollo local y un mejor cuidado ambiental, atendiendo los daños que consideraban eran responsabilidad de la empresa. Para profundizar en el análisis consideramos importante dar cuenta de la estructura discursiva en la cual se articulaban estas demandas. Así, reconocimos que estas demandas eran enunciadas por los agentes locales apelando a diferentes identidades colectivas, dos de ellas relacionadas entre sí: la identidad campesina y la identidad indígena k'ana. Encontramos que a contracorriente del debilitamiento que las comunidades campesinas habían experimentado en Espinar durante las últimas décadas, venía emergiendo una identidad colectiva que permitía cohesionar las resistencias sociales. Se representó así a un «Nosotros» con rostros campesinos e indígenas que veía dañado su estilo de vida por la actividad minera. A través de demandas inscritas en estas superficies identitarias, los agentes locales buscaron legitimar sus planteamientos ante la opinión pública local. Progresivamente los agentes locales no solo reconocieron la alteridad en la empresa minera sino también en el gobierno nacional, al identificarlo -por su proceder- como aliado de aquella. El conflicto socioambiental en Espinar del año 2012 adquirió una intensidad que dio paso a un antagonismo que terminó siendo reprimido por el gobierno nacional. Lo ocurrido en Espinar en el 2012 dejó como saldo el arresto de autoridades y dirigentes sociales, así como dos personas muertas y decenas de heridos. El gobierno de Ollanta Humala declaró el Estado de Emergencia e instaló una mesa de diálogo para canalizar las demandas de la población.

Ahora bien, para tener una comprensión más integral del conflicto socioambiental en Espinar decidimos considerar también en nuestro análisis la capacitad de interpelación de los discursos enunciados por los agentes locales en sus destinatarios. En ese sentido, reconocimos la centralidad de la identidad campesina en Espinar, vinculada a memorias colectivas en torno a resistencias sociales ocurridas en la historia política local. Identificamos también cómo los discursos de los agentes locales disputaban sentidos construidos no solo por el gobierno en su afán de legitimar las condiciones en las cuales operaban las empresas mineras, sino también por la propia minera

Matriz 1. Propiedades y dimensiones para el análisis del discurso

\begin{tabular}{|l|l|l|}
\hline Propiedades & Dimensiones & Caso de estudio: \\
\hline Condiciones de producción & Régimen político & $\begin{array}{l}\text {-Gobierno nacional promotor de la actividad minera. } \\
\text {-Gobierno local crítico a la actividad minera. }\end{array}$ \\
\cline { 2 - 3 } & Actividades económicas & $\begin{array}{l}\text {-Industria minera a gran escala. } \\
\text {-Agricultura y ganadería. }\end{array}$ \\
\hline \multirow{5}{*}{ Lógicas de articulación } & Prodestinatarios & $\begin{array}{l}\text {-Las comunidades campesinas. } \\
\text {-El pueblo K'ana". } \\
\text {-La población urbana de Espinar crítica a la actividad minera. }\end{array}$ \\
\cline { 2 - 3 } & Contradestinatario & $\begin{array}{l}\text {-La empresa minera. } \\
\text {-El gobierno nacional. }\end{array}$ \\
\cline { 2 - 3 } & Paradestinatario & -La población de Espinar que no participa en las protestas. \\
\cline { 2 - 3 } & Nodos discursivos & $\begin{array}{l}\text {-La convivencia en armonía. } \\
\text {-Desarrollo local } \\
\text {-Cuidado del medio ambiente }\end{array}$ \\
\hline \multirow{2}{*}{ Condiciones de reconocimiento } & Identidades sedimentadas & $\begin{array}{l}\text {-La identidad campesina. } \\
\text {-Memorias colectivas de resistencia. }\end{array}$ \\
\cline { 2 - 3 } & Discursos en disputa & $\begin{array}{l}\text {-La minería como promotora del desarrollo. } \\
\text {-La responsabilidad social empresarial. }\end{array}$ \\
\hline
\end{tabular}

Fuente: elaboración propia 
a través de sus programas de responsabilidad social empresarial.

La referencia a este estudio de caso ha buscado ejemplificar de forma sintética nuestra propuesta de análisis, evidenciando tres propiedades del discurso que consideramos fundamentales estudiar: las lógicas de articulación que genera, sus condiciones de producción y las condiciones de reconocimiento (ver Matriz 01). A partir del ya citado trabajo de Retamozo y Fernández (2010), en las siguientes líneas profundizaremos en cada una de estas propiedades y sus dimensiones.

\subsection{Las lógicas de articulación del discurso}

Cuando analizamos la producción social de sentidos debemos considerar que esta se encuentra afectada por la indeterminación, es decir, no responde a una literalidad que debemos develada (desentrańando la intención del enunciador, por ejemplo), sino más bien implica una relación entre producción y recepción en el seno de intercambios discursivos. Esto explica la imposibilidad de fijar de manera perpetua los sentidos que organizan la vida social y, más bien, la permanente disputa por posicionar determinados significados. ${ }^{21}$

De hecho, la polisemia que caracteriza a la semántica política se explica antes que, por la ausencia de acuerdos racionales en torno a los significados de los conceptos, por la contraposición de diferentes experiencias colectivas. Es decir, la polisemia no responde a un problema de racionalidad sino a motivos experienciales y de disputa política.

Ahora bien, la organización de la vida social no puede sostenerse sobre la base de una polisemia absoluta, necesita fijar (aunque siempre de forma limitada) ciertos sentidos organizadores. Esta acción es posible a través de puntos nodales que posibilitan prácticas de articulación discursiva. Los puntos nodales intervienen en los sentidos que adquieren los elementos que forman parte de la estructura discursiva. Por ejemplo, los significantes «inversión» $\mathrm{y}$ "crecimiento" cumplen una función fundamental en la estructura discursiva neoliberal, imprimiendo un sentido parti-

21 Recordemos que Volóshinov ya en 1929 destacó que rastrear la polisemia en los conceptos nos podría ayudar a acercarnos al terreno de lo político desde la disputa por los sentidos. El lingüista ruso afirmó que «El signo llega a ser la arena de la lucha de clases» (2009:47). cular en el significante "Desarrollo». Los puntos nodales deben ser capaces de condensar una diversidad de significados para cumplir su rol articulador. Este rol es el que posibilita una relativa estabilidad al flujo de la heterogeneidad social poniendo en operación lógicas equivalenciales. A través de estas prácticas articulatorias es que podemos rastrear la constitución de identificaciones políticas. ${ }^{22}$ Lo que está en juego en estas prácticas es transcender la parcialidad de determinadas identidades inscribiéndolas en referencias identitarias más amplias (Laclau y Mouffe, 2004).

Cuando analizamos la constitución de las identidades políticas en las democracias contemporáneas debemos considerar un triple dispositivo de enunciación: los prodestinatarios, los contradestinatarios y los paradestinatarios, tres entidades del imaginario político. Los prodestinatarios nos remiten al «nosotros» o colectivo de identificación que comparte determinadas convicciones políticas. Los contradestinatarios refieren a la alteridad que cuestiona las convicciones políticas del colectivo de identificación. Los paradestinatarios, por su parte, remiten a los colectivos de «indecisos» que buscan ser interpelados por los colectivos en discordia (Verón, 1987). Como podemos ver, en la constitución de las identificaciones colectivas se va, a su vez, configurando el campo político. ${ }^{23}$

Debemos recordar que las identidades políticas por más sedimentadas que se encuentren no son estáticas, todo lo contrario, experimentan reactivaciones (históricas y contingentes) que se manifiestan en, por ejemplo, la resignificación de los conceptos políticos

22 Sobre el concepto de articulación ver: Laclau y Mouffe, 2004:142155. Como antecedente de este concepto podemos referir a la «sobredeterminación", concepto althusseriano que hace referencia a la acumulación de contradicciones de distinta índole (económicas, políticas, ideológicas, etc.) que convergen en una formación social determinada (De Ípola, 2012:134). La diferencia fundamental de ambos conceptos es que mientras en la sobredeterminación althusseriana (por lo menos en su versión original) no se renuncia a la apelación de la determinación en última instancia de las relaciones económicas sobre el todo social; en el concepto de articulación propuesto por Laclau y Mouffe no se postula ningún fundamento último del orden social.

23 En esta configuración del campo político operan cuatro componentes a través de las cuales el enunciador construye su red de relaciones con las entidades del imaginario: el descriptivo, el didáctico, el prescriptivo y el programático. El primero remite a la constatación de determinados hechos que busca destacar el enunciador; el segundo refiere al conocimiento y apelación a principios universales; el tercero al deber ser, a la necesidad deontológica; y el cuarto refiere al orden del poder hacer, al tiempo futuro (Verón, 1987:20-22). 
y las memorias colectivas que definen sus horizontes de sentido. Estas reactivaciones se producen en el marco de las disputas políticas por la organización de la vida social y pueden implicar complejos procesos de articulación de significantes que apelan a gramáticas disímiles (jurídicas, religiosas, políticas, etc.). Como veremos a continuación, la capacidad de un significante para asumir una lógica equivalencial se encuentra habilitada por condiciones de producción y de reconocimiento del discurso.

\subsection{Las condiciones de producción del discurso}

Debemos recordar que partimos del reconocimiento de la autonomía relativa de lo político. En tal sentido, asumimos que toda producción discursiva se realiza en ciertas condiciones de posibilidad. Es decir, la producción discursiva no se realiza ex nihilo, sino que se ve condicionada por sedimentaciones que organizan la vida social y que orientan tanto la producción como el reconocimiento de los discursos políticos. En tal sentido, en las sociedades contemporáneas la producción social de sentidos está condicionada por las prácticas de la democracia liberal y a actividades económicas usualmente vinculadas al modo de producción capitalista. Las reglas, procedimientos e instituciones que definen a la democracia liberal influirán en las prácticas articulatorias que pondrán en marcha los agentes políticos. A su vez, las lógicas de producción, consumo y acumulación de capital podrán dejar su impronta en la enunciación política.

Cabe precisar que las condiciones de producción del discurso arriba señaladas no escapan a los procesos de significación. En tal sentido, para comprender cómo operan en la acción política debemos analizar los sentidos que los agentes les adscriben. Las estructuras socioeconómicas y políticas no escapan a los procesos de significación social, no son realidades externas a estos procesos.

\subsection{Las condiciones de reconocimiento del discurso}

Las condiciones de reconocimiento dan cuenta de la posibilidad de que un discurso genere procesos de identificación política. Implica reconocer la relación entre la producción y la recepción de sentidos en el seno de intercambios discursivos. En esta propiedad del discurso operan factores tales como las identifi- caciones previas y otros discursos en pugna (Sigal y Verón, 2010; Retamozo y Fernández, 2010).

Para el estudio de las identificaciones previas o sedimentadas, encontramos la presencia de las memorias colectivas. Por ejemplo, en nuestro análisis del conflicto socioambiental de Espinar hemos dado cuenta de cómo ciertas memorias colectivas en torno a las resistencias frente a distintas amenazas a los territorios, operaron en la articulación de diferentes agentes locales y orientaron sus acciones colectivas para hacer frente a la expansión de la actividad minera a gran escala. Nuestro análisis dio cuenta de la relación entre identificaciones políticas y memorias colectivas a través de la apelación de los agentes locales a acontecimientos, personajes y lugares que remitían a ciertas prácticas de solidaridad pasadas, los cuales orientaron las experiencias presentes de resistencia (Duárez, 2018).

Además de las memorias colectivas otros estudios han dado cuenta de la importancia de las tradiciones políticas para el estudio de las identidades políticas. Gerardo Aboy Carlés en sus trabajos sobre las identidades políticas ha dado cuenta de cómo operan las tradiciones políticas en la cohesión del «nosotros», las cuales suponen «un tipo especial de intervención intelectual que aísla y filia determinadas recurrencias tópicas sobre un conjunto de prácticas sociales empíricas y teóricas» (2016:07). ${ }^{24}$ Las tradiciones políticas son una suerte de "marcos de referencia» para la acción colectiva. Socialismo, republicanismo y liberalismo son algunos ejemplos. Para el caso peruano podemos destacar al aprismo.

Las tradiciones políticas experimentan reactivaciones a través del desplazamiento de los sentidos que las organizan. La denominada historia conceptual nos brinda una base bastante sólida para comprender lo que está aquí en juego. Si hemos afirmado, siguiendo a Aboy Carlés, que en las tradiciones políticas operan prácticas teóricas, un elemento clave entonces son los conceptos. Los conceptos pueden operar como puntos nodales de un discurso. Ahora bien, desde la historia conceptual los conceptos políticos deben asumirse como históricamente condicionados,

24 Aboy Carlés es uno de los intelectuales que más aportes ha brindado para el estudio del populismo. Entre sus trabajos se encuentran: «Repensando el populismo» (2003), «Populismo, regeneracionismo y democracia» (2010) y "De lo popular a lo populista o el incierto devenir de la plebs» (2013). 
no podemos apelar a cualquier supuesto sustancialista inherente a los mismos. Es decir, nos encontramos lejos de una supuesta "historia de las ideas» para más bien subrayar -siguiendo a Koselleck- que los conceptos condensan experiencias históricas. En tal sentido, los conceptos no son atemporales sino más bien imprimen sentido a las experiencias colectivas confluyendo o entrecruzando referencias al pasado (tradiciones y memorias), al presente (la contingencia) y al futuro (perspectivas de acción y realización). Para su análisis debemos prestar atención tanto a la significación asumida por un concepto al interior de un determinado discurso político, como a las resignificaciones que experimenta al dar cuenta de sus contextos de experiencia (Chignola, 2009; Duso, 2009).

Por último, si hemos planteado el estudio de las identificaciones políticas desde el reconocimiento del antagonismo, nuestro análisis debe dar cuenta también de los discursos en disputa en un campo político. El análisis de discurso debe describir y comprender las disputas de sentido, las intervenciones discursivas de los distintos agentes en disputa. Para el caso de estudio de Espinar, referimos a las disputas entre las reivindicaciones de los agentes locales, la responsabilidad social de la empresa minera y la defensa gubernamental a la actividad minera. Otro ejemplo que podemos referir es la disputa por la memoria en torno a los acontecimientos políticos de los años noventa, en donde fujimoristas y anti-fujimoristas enuncian interpretaciones disímiles. Este análisis nos permite comprender las fronteras identitarias que organizaron el campo político.

\section{Conclusiones}

A partir de una crítica al enfoque de la política acotada practicada en los últimos ańos por la ciencia política en el Perú, nuestro artículo propone un camino alternativo para el análisis de los procesos políticos. Valiéndonos del enfoque posfundacional, hemos propuesto asumir al antagonismo como objeto de estudio. De esta manera hemos buscado aportar al desarrollo de un pluralismo de enfoques teóricometodológicos sin renunciar al reconocimiento de la autonomía relativa de lo político. Vale la pena aclarar, por tanto, que no asumimos una descalificación académica de lo que aquí se describió como una concep- ción acotada de la política. Lo que nos interesa más bien es, a partir de identificar los límites de esta concepción (su reificación del régimen político), ensayar caminos alternativos de análisis.

Hemos asumido la fundamental distinción conceptual entre la política y lo político para definir al antagonismo como objeto de estudio. Consideramos que dicha distinción conceptual nos habilita todo un campo de estudio poco explorado o visitado por la ciencia política en el Perú para dar cuenta de las limitaciones institucionales para mediar en los conflictos sociales que perturban el orden social (Arce, 2015). Hemos destacado cómo a través del antagonismo se constituyen las identificaciones políticas y se define el campo político, condicionando no solo el funcionamiento del régimen político, sino incidiendo más allá de sus fronteras institucionales.

Destacamos también los aportes que nos brinda el análisis del discurso para el estudio del antagonismo y de los procesos de identificación política que involucra. Planteamos orientaciones teórico-metodológicas ya que el estudio de los procesos políticos no solo demanda de conceptos que iluminen la labor del investigador o investigadora, sino también de ciertas pautas que podrían resultar útiles para el proceso «artesanal» de análisis de información. En tal sentido, hemos propuesto tres propiedades a considerar en el análisis del discurso: lógicas de articulación, condiciones de producción y condiciones de reconocimiento. Cada una de estas propiedades podrán ser desagregadas en dimensiones en función de las unidades de análisis a estudiar. Cabe indicar que uno de los principales desafíos del análisis que proponemos es dar cuenta del carácter procesual, histórico de lo político, es decir, de la relación entre estructuras sedimentadas y la acción que permite reactivar dichas estructuras, modificándolas.

En perspectiva, consideramos importante destacar al menos dos desafíos teóricos a partir de lo planteado en este artículo. El primero de ellos involucra a la teoría democrática y el antagonismo. ¿Cómo la democracia puede procesar el momento disruptivo del antagonismo? Para responder a esta pregunta, Mouffe (2000:51-72;93-118) ha propuesto una lectura crítica de la obra de Schmitt, planteando una alternativa a la distinción amigo/enemigo a partir de la «domesticación» del antagonismo. Esta alternativa es denominada por la autora como agonismo la cual 
«establece una relación nosotros/ellos en la que las partes en conflicto, si bien admitiendo que no existe una solución racional a su conflicto, reconocen sin embargo la legitimidad de su oponente» (2009:27). La propuesta de Mouffe nos brinda algunas pistas para la reflexión. El segundo de ellos refiere a la teoría de la hegemonía. Si asumimos que el orden social está fundado en relaciones de poder, debemos afinar nuestro instrumental teórico-metodológico para dar cuenta de los procesos a través de los cuales una parte asume la representación de un determinado espacio político (Laclau y Mouffe, 2004).

Podemos concluir que un análisis de los procesos políticos que ponga en el centro de su atención al antagonismo y a las identificaciones políticas también brinda elementos para comprender los desafíos presentes para la representación y la construcción de consensos que permitan cimentar un régimen político democrático. Claro está, reconociendo la precariedad de todo cimiento, aceptando aquella fluidez a la que el Eclesiastés refiere en nuestro epígrafe.

\section{Bibliografía}

Авоч, Gerardo (2016). «Populismo у democracia liberal: Una tensa relación», en Identidades, $\mathrm{N}^{\circ}$ 14: 0526, Instituto de Estudios Sociales y Políticos de la Patagonia, Chubut.

Aragón, Jorge e Incio, José Luis (2014). «La re-elección de autoridades regionales y municipales en el Perú, 20062014», en Revista Argumentos, Nº 05, IEP, Lima.

ArCE, Moisés (2015). La extracción de los recursos naturales y la protesta social en el Perú. Lima: PUCP.

Bоввіо, Norberto (2010). Liberalismo y democracia. México: Fondo de Cultura Económica.

Ccahunana, Jorge (2019). "La reforma educativa de 1905: Estado, indígenas y políticas racializadas en la República Aristocrática», en Apuntes, No 86: 05-32, Universidad del Pacífico, Lima.

Chignola, Sandro (2009). «Historia de los conceptos y de la filosofía política. Sobre el debate en Alemania». En Sandro Chignola y Giuseppe Duso, Historia de los conceptos y filosofía política: 39-77. Espańa: Biblioteca Nueva.

Comisión de Alto Nivel Para la Reforma Política (2019). Hacia la Democracia del Bicentenario. Lima: Konrad Adenauer Stiftung.
Dargent, Eduardo y Muñoz, Paula (2012). «Perú 2012: Continuidades y cambios en la política sin partidos», en Revista de Ciencia Política, No 01: 245-268, Pontificia Universidad Católica de Chile, Santiago de Chile.

De Ípola, Emilio (2012). «<Louis Althusser y Jacques Derrida. La fuerza de la amistad $>$. En Alejandro Lezama y Emilio de Ípola, Althusser. Una introducción: 124-138, Buenos Aires: Editorial Quadrata Biblioteca Nacional.

De Ípola, Emilio (2007). Althusser, el infinito adiós. Argentina: Siglo veintiuno editores.

DuÁrEZ, Jorge (2020). «Expansión minera y politización de las identidades étnicas (2002-2012). Los casos de Abra Pampa (Jujuy-Argentina) y Espinar (Cusco-Perú)», en Andes. Antropología e Historia, Vol. 31, № 02: 1-36, ICSOH y CONICET, Salta.

DuÁrez, Jorge (2018). «Política y usos de la memoria en los Andes durante los ańos del boom minero (19982012). Los casos de Abra Pampa (Argentina) y Espinar (Perú)», Identidades, No 14: 175-194, Instituto de Estudios Sociales y Políticos de la Patagonia, Chubut.

DuÁrez, Jorge (2018). «Ser aprista en tiempos neoliberales. Un análisis discursivo del segundo gobierno de Alan García Pérez (2006-2011)», en Temas y Debates, $\mathrm{N}^{\circ}$ 36: 113-136, Universidad Nacional de Rosario, Rosario.

DuÁrez, Jorge (2017). Identificaciones políticas y conflictos socioambientales en los Andes. Los casos de Abra Pampa (Jujuy-Argentina) y Espinar (Cusco-Perú) 2004-2012. Argentina: Universidad Nacional de San Martín.

Duso, Giuseppe (2009). «La historia de la filosofía política: entre historia conceptual y filosofía». En Sandro Chignola y Giuseppe Duso, Historia de los conceptos y filosofía política: 323-349. Espańa: Biblioteca Nueva.

Franco, Carlos (2013). Acerca del modo de pensar la democracia en América Latina. Argentina: Ediciones de la Universidad Nacional de Lanús.

Garavito, Hugo (1989) El Perú liberal. Partidos e ideas políticas de la Ilustración a la República Aristocrática. Lima: Editorial El Virrey.

Laclau, Ernesto (2006). La razón populista. México: Fondo de Cultura Económica.

Laclau, Ernesto y Mouffe, Chantal (2004). Hegemonía y estrategia socialista. Hacia una radicalización de la democracia. Argentina: Fondo de Cultura Económica. 
Laclau, Ernesto (1993). Nuevas reflexiones sobre la revolución en nuestro tiempo. Buenos Aires: Ediciones Nueva Visión.

LaClau, Ernesto (1985). "Tesis acerca de la forma hegemónica de la política». En Martín Labastida (coord.), Hegemonía y alternativas políticas en América Latina: 19-44. México: Siglo XXI Ediciones e Instituto de Investigaciones Sociales, UNAM.

Marchart, Oliver (2009). El pensamiento político posfundacional. La diferencia política en Nancy, Lefort, Badiou y Laclau. Buenos Aires: Fondo de Cultura Económica.

Meléndez, Carlos y Vergara, Alberto (Ed.) (2010). La iniciación de la política. El Perú político en perspectiva comparada. Lima: PUCP.

Mouffe, Chantal (2009). En torno a lo político. Argentina: Fondo de Cultura Económica.

Mouffe, Chantal (2000). La paradoja democrática. El peligro del consenso en la política contemporánea. España: Gedisa.

O’Donnell, Guillermo (2004). La Democracia en América Latina. Hacia una democracia de ciudadanas y ciudadanos. Buenos Aires: PNUD.

Ranciere, Jacques (1996). El desacuerdo. Política y filosofía. Buenos Aires: Nueva Visión.
Retamozo, Martín y Fernández, Mariano (2010). «Discurso político e identidades políticas: producción, articulación y recepción en las obras de Eliseo Verón y Ernesto Laclau», en Cuadernos de H Ideas, No 04: 0122, Universidad Nacional de La Plata, La Plata.

Sigal, Silvia y Verón, Eliseo (2010). Perón o muerte. Los fundamentos discursivos del fenómeno peronista. Argentina: Eudeba.

Staten, Henry (1984). Wittgenstein and Derrida. London: University of Nebraska Press.

SuÁrez, Fernando (2015). «Ni con Laclau, ni contra Laclau. Críticos y críticas a La Razón Populista», en Identidades, $\mathrm{N}^{\circ}$ 09: 64-82, Instituto de Estudios Sociales y Políticos de la Patagonia, Chubut.

Tanaka, Martín (2005). Democracia sin partidos. Perú, 2000-2005. Los problemas de representación y las propuestas de reforma política. Lima: IEP.

Verón, Eliseo (2004). La semiosis social. Buenos Aires: Gedisa.

Verón, Eliseo (1987). «La palabra adversativa. Observaciones sobre la enunciación política». En Leonor Arfuch y otros, El discurso político: lenguajes y acontecimientos: 13-26, Buenos Aires: Hachette.

Volóshinov, Valentín (2009). El marxismo y la filosofía del lenguaje. Buenos Aires: Editorial Godot. 